\title{
Evaluation of Thermal Comfort in Hyperbaric Oxygen Chamber
}

\author{
Hu Zhuohuan ${ }^{a}$, Yang Xin $^{\mathrm{b}^{*}}$ and Yang Mo ${ }^{\mathrm{c}}$ \\ University of Shanghai for Science and Technology, Shanghai, China \\ a huzhuohuan@hotmail.com, bhappyyang1215@126.com, ${ }^{\mathrm{c}}$ yangm66@gmail.com
}

Keywords: hyperbaric oxygen chamber; thermal comfort; inlet angle

\begin{abstract}
Indoor thermal environment of a hyperbaric oxygen chamber was researched by computational fluid dynamics to figure out the relationship between the inlet angle with thermal sensation index. Steady k- $\varepsilon$ turbulence model and incompressible fluid flow of constant property have been considered, the heat dissipation due to the viscous force was ignored. The results show the air temperature field and flow field are largely affected by inlet angles. High air velocity can enhance the effect of convective heat transfer, and it may causees draught. Even a small change in inlet temperature will cause a great impact on thermal comfort index. Appropriate refrigerating capacity and matching inlet angle are the prerequisite of a satisfactory thermal comfort.
\end{abstract}

\section{Introduction}

The hyperbaric chamber is a type of pressure vessels for human occupancy with high pressure, good sealing and other characteristics [1]. Patients will stay in the chamber for a long time during the hyperbaric oxygen therapy, so the thermal comfort in a hyperbaric chamber is very crucial.

Thermal comfort is regarded as one of important building performance indicators [2]. The American Society of Heating, Refrigerating and Air-Conditioning Engineers (ASHRAE) defined it as "the condition of the mind in which satisfaction is expressed with the thermal environment" [3]. There are many researchers carried out to investigate the parameters which affected thermal comfort in the past $[4,5]$. The most referred research in the field of thermal comfort was carried out by Fanger in the 1970s, in which he developed an empirical model named Predicted Mean Vote (PMV) [6]. In order to keep consistent with the 7-point ASHRAE thermal sensation scale, the results of the equation are divided into seven levels, from cold $(-3)$ to hot $(+3)$ with neutral in the middle (Table I) [7]. But even under same condition thermal sensation can be different among different people. So Fanger developed a model named Predicted Percent Dissatisfied (PPD), which means the percentage of people who will be dissatisfied with the thermal environment. The PMVPPD standards were prescribed by ISO 7730 in 1984 . And the recommended value of PMV index is between -0.5 to 0.5 . The value of PPD index is under $10 \%$ [8]. Wong conducted a field test of thermal comfort in Singapore in which there were totally 506 participants [9].

Table I The 7-point ASHRAE thermal sensation scale

\begin{tabular}{|c|c|c|c|c|c|c|c|}
\hline PMV & $-\mathbf{3}$ & $\mathbf{- 2}$ & $\mathbf{- 1}$ & $\mathbf{0}$ & $\mathbf{+ 1}$ & $\mathbf{+ 2}$ & $\mathbf{+ 3}$ \\
\hline Thermal sensation & Cold & Cool & Slightly cool & Neutral & Slightly warm & Warm & Hot \\
\hline
\end{tabular}

In this paper, air distribution characters of velocity and thermal comfort with different inlet angle and different inlet temperature will be discussed.

\section{Numerical simulate}

Fanger related the PMV to the imbalance between the actual heat flows from a human body in a given environment by the following Eq. 1[10]:

$$
\begin{aligned}
& \mathrm{PMV}=[0.303 \times \exp (-0.036 \mathrm{M})+0.0275] \times\left\{\mathrm{M}-\mathrm{W}-3.05 \times\left[5.37-0.007 \times(\mathrm{M}-\mathrm{W})-\mathrm{P}_{\mathrm{a}}\right]-0.0173 \times \mathrm{M} \times\left(5.87-\mathrm{P}_{\mathrm{a}}\right)\right. \\
& \left.-0.0014 \times \mathrm{M} \times\left(34-\mathrm{t}_{\mathrm{a}}\right) \times 0.42 \times(\mathrm{M}-\mathrm{W}-58)-3.96 \times 10^{-8} \times \mathrm{f}_{\mathrm{cl}} \times\left[\left(\mathrm{t}_{\mathrm{cl}}+273\right)^{4}-\left(\mathrm{t}_{\mathrm{r}}-273\right)^{4}\right]-\mathrm{f}_{\mathrm{cl}} \times \mathrm{a}_{\mathrm{c}} \times\left(\mathrm{t}_{\mathrm{cl}}-\mathrm{t}_{\mathrm{a}}\right)\right\}
\end{aligned}
$$


Where $\mathrm{M}$ refers to heat production rate of human metabolism, $\mathrm{W} \cdot \mathrm{m}^{-2} ; \mathrm{W}$ refers to the external work, $\mathrm{W} \cdot \mathrm{m}^{-2} ; \mathrm{P}_{\mathrm{a}}$ refers to the vapor pressure in the air, $\mathrm{kPa} ; \mathrm{t}_{\mathrm{a}}$ refers to the ambient temperature, ${ }^{\circ} \mathrm{C}$; $\mathrm{t}_{\mathrm{r}}$ refers to the mean radiant temperature, ${ }^{\circ} \mathrm{C}$; $\mathrm{t}_{c l}$ refers to mean temperature of outer surface of the clothed body, ${ }^{\circ} \mathrm{C}$.

$$
t_{C l}=\frac{35.7-0.0275(M-W)-R_{\mathrm{cl}} f_{\mathrm{cl}}\left[4.13(1+0.01 \mathrm{~d} T)+\mathrm{a}_{\mathrm{c}} t_{a}\right]}{1+R_{\mathrm{cl}} f_{C l}\left[4.13(1+0.01 d T)+\mathrm{a}_{\mathrm{c}}\right]}
$$

Where $\mathrm{R}_{\mathrm{cl}}$ is thermal resistance of clothing, $\mathrm{m}^{2} \cdot \mathrm{K} / \mathrm{W} ; \mathrm{f}_{\mathrm{cl}}$ is the clothing area factor.

$$
f_{c l}=\frac{F_{C l}}{F_{D}}=1+0.968 R_{c l}
$$

Where $\mathrm{F}_{\mathrm{cl}}$ is the surface area of clothed body, $\mathrm{F}_{\mathrm{D}}$ is the surface area of nude body.

$$
\mathrm{PPD}=100-95 \times \exp \left[-\left(0.03353 \times P M V^{4}+0.219 \times P M V^{2}\right)\right]
$$

Fig. 1 shows the air conditioning system of hyperbaric oxygen chamber [1]. The advantages of this system are as follows:

(1) It can refresh the air in the chamber, and keep the clean environment.

(2) The oxygen concentration in the chamber will be reduced.

(3) The air circulation in the chamber will be enhanced.

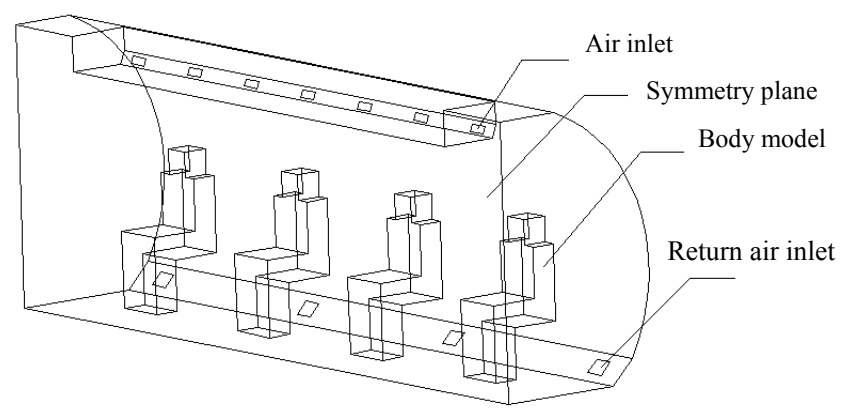

Fig.1 The air conditioning system of the hyperbaric oxygen chamber

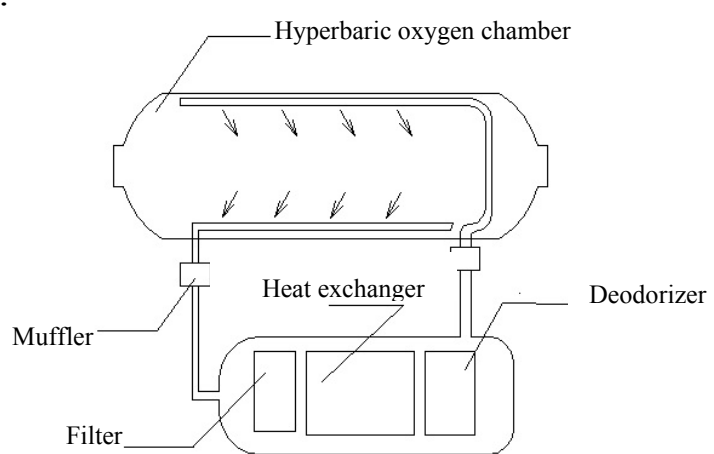

Fig.2 Simplified model of the oxygen chamber

This research establishes a hyperbaric oxygen chamber model, which could accommodate eight simplified body models. And the body models are steady heat source. A plane is set up to observe the air temperature, air velocity and the PMV-PPD index around the body models. The Fig.2 shows a simplified model of the oxygen chamber.

The following air inlet angles of the different air inlets: $a=40^{\circ}, b=60^{\circ}, c=80^{\circ}$ are studied in this paper. Table II shows the boundary conditions, the model's operation pressure is 200,000pa. And 5

\begin{tabular}{|c|c|c|c|c|c|}
\hline & \multicolumn{5}{|c|}{ Type and parameter of boundary condition } \\
\hline Air inlet & \multicolumn{5}{|c|}{ Velocity inlet boundary condition with $4 \mathrm{~m} / \mathrm{s}$} \\
\hline Return air inlet & \multicolumn{5}{|c|}{ outflow } \\
\hline Body model & \multicolumn{5}{|c|}{ No slip boundary condition with heat flux of $50 \mathrm{w} / \mathrm{m}^{2}$} \\
\hline Others & \multicolumn{5}{|c|}{ No slip boundary condition with adiabatic wall } \\
\hline \multicolumn{6}{|c|}{ Table III Cases studies } \\
\hline & Case1 & Case2 & Case3 & Case4 & Case5 \\
\hline Inlet angle $\left[{ }^{\circ}\right]$ & 40 & 60 & 80 & 60 & 60 \\
\hline Temperature [K] & 294 & 294 & 294 & 290 & 292 \\
\hline
\end{tabular}
cases are researched in this paper. Table III shows the inlet angle and inlet temperature in each cases.

Table II Boundary conditions

\section{Results and discussion}

Fig.3, Fig.4, Fig.5 showed the simulation results of case1, case 2 and case3. They show the temperature contours at the mid-plane, it can be seen that the air temperature in the chamber is maintained at $295 \sim 296.5 \mathrm{~K}$ due to the human heat production. The air temperature in which close 
to the top of chamber is below to $295 \mathrm{~K}$, the area in which temperature between $295.6 \mathrm{~K} \sim 296.5 \mathrm{~K}$ is expanding with the increase of the inlet angle. The air velocity range in the chamber is between 0.15 1m/s in Fig.3(b). But in some area of Fig.4 (b) and Fig.5(b) , the air velocity is out of this range. The velocity in the region which close to the top of chamber is larger than 1.

The magnitude of predicted PMV index is between $0.5 \sim 2$ in case 1 3 conditions, that means the patients will feel warm during the treatment in the hyperbaric oxygen chamber. There are two main reasones for this resulat: a. the inlet air temperature is a little high; $b$. the air supply method is not good enough. The convective heat transfer intensity is not enough with the low air velocity, and it leads to the magnutide of the PMV index in this area is higher than 1 . It leads to that the value of PPD index around human body is higher than 30 in these cases. This is consistent with the results of the PMV contour.

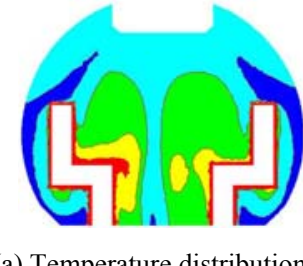

(a) Temperature distribution

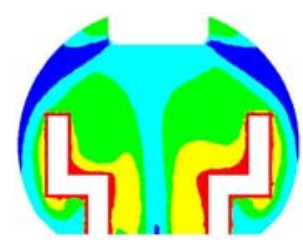

(a) Temperature distribution

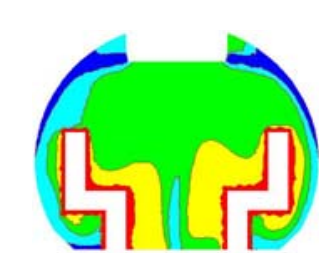

(a) Temperature distribution

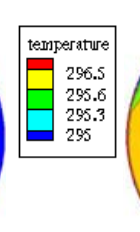

(b)

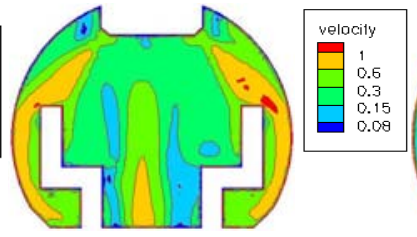

(b) Velocity distribution Fig. 3 Simulate

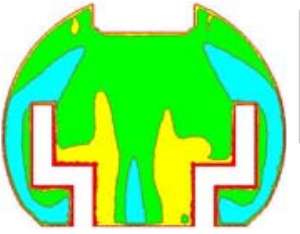

(c) PMV distribution \begin{tabular}{l} 
result with \\
$\mid$\begin{tabular}{|l|}
\hline velocity \\
1 \\
0.6 \\
0.3 \\
0.15 \\
0.08 \\
\hline
\end{tabular} \\
\hline
\end{tabular}

inlet angle with $40^{\circ}$

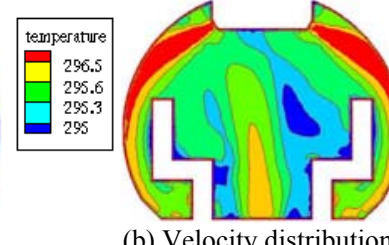
Fig.4 Simulate result with inlet air angle with $60^{\circ}$

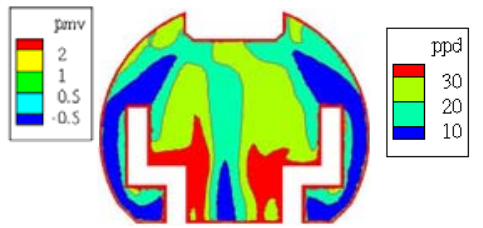

(d) PPD distribution

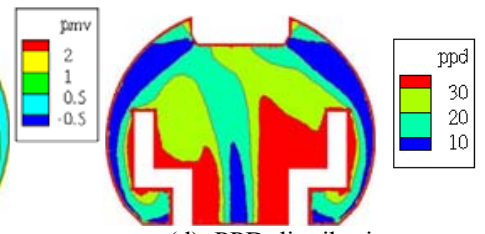

(d) PPD distribution

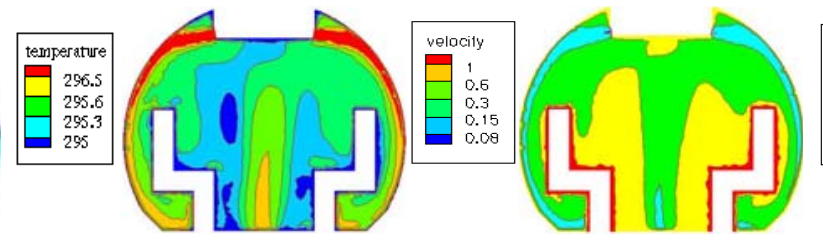

(b) Velocity distribution

(c) PMV distribution

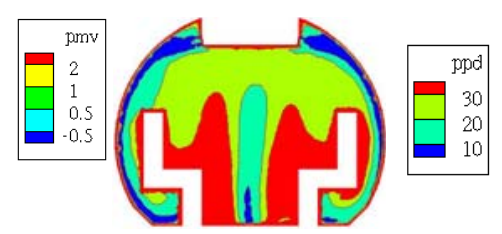

(d) PPD distribution Fig. 5 Simulate result with inlet air angle with $80^{\circ}$

Fig.6, Fig.7 are the simulation results of case 4 and case5. When the inlet air temperature is $290 \mathrm{~K}$, the temperature range in chamber mainly in $291 \mathrm{~K} \sim 293 \mathrm{~K}$; when the inlet air temperature is $292 \mathrm{~K}$, the temperature range mainly in $293 \mathrm{~K} \sim 295 \mathrm{~K}$; when the inlet air temperature is $294 \mathrm{~K}$, the temperature range mainly in $295 \mathrm{~K} \sim 297 \mathrm{~K}$. The air velocity distribution of hyperbaric oxygen chamber is roughly the same in three cases.

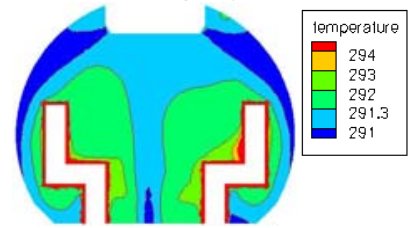

(a) Temperature distribution

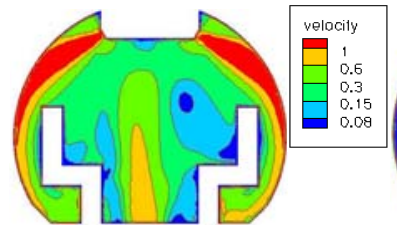

(b) Velocity distribution

Fig.6 Simulate result with inlet air temperature with $290 \mathrm{~K}$

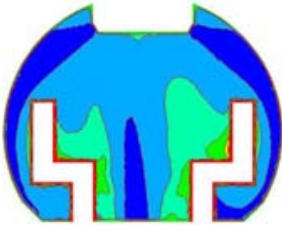

(c) PMV distribution

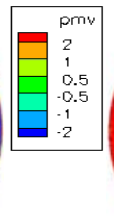

(d) PPD distribution

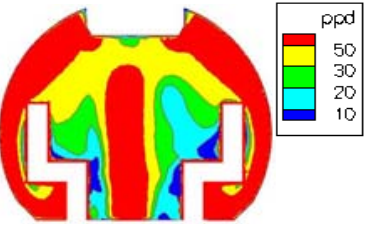

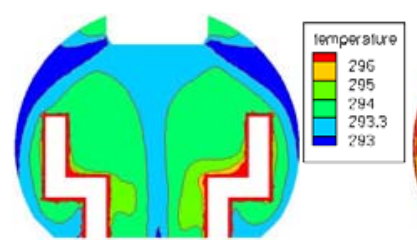

(a) Temperature distribution

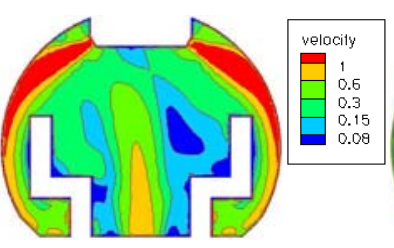

(b) Velocity distribution

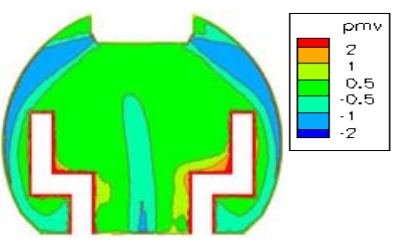

(c) PMV distribution

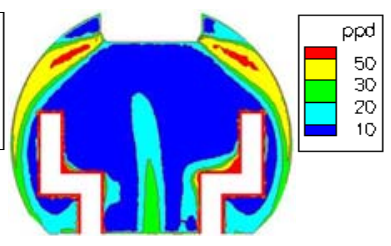

(d) PPD distribution

Fig.7 Simulate result with inlet air temperature with $292 \mathrm{~K}$

With the decrease of inlet air temperature, the PMV value of case 4 and case 5 are decreased. As shown in Fig.6 (c), the value of PMV is generally lower than -0.5 . This phenomenon is known as 
draught, Fanger defined draught as "an unwanted local cooling of the human body caused by air movement ". Draught is closely related to air temperature and air velocity. In order to avoid the discomfort caused by draught, the human body is limited to a place in which temperature is not too low, and the air velocity is not too fast.

The result of Fig.7 shows a satisfactory thermal comfort condition of the chamber. The temperature around people is between 293K and $295 \mathrm{~K}$, and the PMV-PPD index accordance with the recommended value. Through the research on the influence of the air supply temperature on the thermal comfort, we found that the proper temperature is very important to the thermal comfort.

\section{Conclusion}

In this paper, we discussed the air distribution characters of velocity and temperature in a hyperbaric oxygen chamber with different inlet angles and air temperature. And we drew the following conclusiones:

(1) Because of the body's metabolism, the air temperature in a hyperbaric oxygen chamber will increase $1 \sim 3^{\circ} \mathrm{C}$ than without patients.

(2) The influence of different inlet angles on velocity field is obvious. High air rate can improve the effects of convection heat transfer. When the air temperature is slightly higher, the thermal comfort index will stay at a high level. But if the ambient temperature is too low, it may lead to a sense of draught.

(3) The thermal comfort of the chamber is closely related to temperature. Even two degrees Celsius temperature difference can result in a significant change in thermal comfort. So appropriate refrigerating capacity and matching inlet angle are the prerequisite of a satisfactory thermal environment.

\section{Acknowledgment}

This work is supported by National Natural Science Foundation of China (No. 51276118), all support is gratefully acknowledged.

\section{References}

[1] Gao Chunjin, Yang Jieyun, and Zhai Xiaohui. Hyperbaric Oxygen Medicine Bases and Clinics, 2008.

[2] Steskens P, Loomans MGLC, Performance indicators for health, comfort and safety of the indoor environment, 10th REHVA World Congress, Antalya, Turkey; 2010.

[3] ANSI/ASHRAE Standard 55. Thermal Environment Conditions for Human Occupancy; 2004.

[4] Parsons KC, Human thermal environments: the effects of hot, moderate, and cold environments on human health, comfort, and performance, Taylor \&Francis, 2003.

[5] Zhang Jili, Ma Liangdong, Zhao Tianyi, Progress of Building Environment Thermal Comfort . Building Energy \& Environment, 2011, 30(1), pp.1-8.

[6] Fanger P O, Calculation of thermal comfort, ASHRAE Transactions, 1966, (73)3, pp.1-20.

[7] Charles KE, Fanger's Thermal Comfort and Draught Models, Institute for Research in Construction National Research Council of Canada, 2003.

[8] ISO 7730. Moderate thermal environments determination of the PMV and PPD indices and specification of the conditions for thermal comfort

[9] N HWong, Shan Shan Khoo. Thermal comfort in classroom in the Tropic, Energy and Buildings, 2003, 35(4), pp.337-351.

[10] Jin Zhaofen, Zhu Yinxin, Built Environment, China Architecture \& Building Press, 2004. 